\title{
Modulation of tumor fatty acids, through overexpression or loss of thyroid hormone responsive protein spot 14 is associated with altered growth and metastasis
}

\author{
Elizabeth A Wellberg ${ }^{1}$, Michael C Rudolph ${ }^{1,3}$, Andrew S Lewis ${ }^{1}$, Nuria Padilla-Just ${ }^{1,2,4}$, Paul Jedlicka ${ }^{1,2}$
} and Steven M Anderson ${ }^{1,2^{*}}$

\begin{abstract}
Introduction: Spot14 (S14), encoded by the THRSP gene, regulates de novo fatty acid synthesis in the liver, adipose, and lactating mammary gland. We recently showed that S14 stimulated fatty acid synthase (FASN) activity in vitro, and increased the synthesis of fatty acids in mammary epithelial cells in vivo. Elevated de novo fatty acid synthesis is a distinguishing feature of many solid tumors compared with adjacent normal tissue. This characteristic is thought to be acquired during tumor progression, as rapidly proliferating cells have a heightened requirement for membrane phospholipids. Further, overexpression of FASN is sufficient to stimulate cell proliferation. While many studies have focused on the FASN enzyme in cancer biology, few studies have addressed the roles of proteins that modify FASN activity, such as S14.
\end{abstract}

Methods: Tumor fatty acids were modulated using two mouse models, mouse mammary tumor virus (MMTV)-neu mice overexpressing S14 and MMTV-polyomavirus middle T antigen (PyMT) mice lacking S14, and associations between elevated or impaired fatty acid synthesis on tumor latency, growth, metastasis, and signaling pathways were investigated. We evaluated S14-dependent gene expression profiles in mouse tumors by microarray and used publicly available microarray datasets of human breast tumors.

Results: S14 overexpression in the MMTV-Neu transgenic model is associated with elevated medium-chain fatty acids, increased proliferation and a shorter tumor latency, but reduced tumor metastasis compared to controls. Loss of S14 in the MMTV-PyMT model decreased FASN activity and the synthesis of medium-chain fatty acids but did not alter tumor latency. Impaired fatty acid synthesis was associated with reduced solid tumor cell proliferation, the formation of cystic lesions in some animals, and decreased phosphorylation of Src and protein kinase B (Akt). Analysis of gene expression in these mouse and human tumors revealed a relationship between S14 status and the expression of genes associated with luminal epithelial differentiation.

Conclusions: This study demonstrates a potential role for S14 in regulating mammary tumor growth and fatty acid synthesis in vivo. Furthermore, these results suggest that modulating the amount of medium chain fatty acids, by changing the levels of S14, has the potential to impact malignant mammary tumor phenotypes.

\footnotetext{
* Correspondence: Steve.Anderson@ucdenver.edu

'Department of Pathology, University of Colorado School of Medicine,

University of Colorado Anschutz Medical Campus, Aurora, CO 80045, USA

${ }^{2}$ Program in Cancer Biology, University of Colorado School of Medicine,

University of Colorado Anschutz Medical Campus, 12801 East 17th Avenue,

Aurora, CO 80045, USA

Full list of author information is available at the end of the article
}

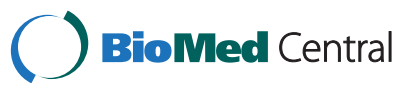

(c) 2014 Wellberg et al.; licensee BioMed Central. This is an Open Access article distributed under the terms of the Creative Commons Attribution License (http://creativecommons.org/licenses/by/4.0), which permits unrestricted use, distribution, and reproduction in any medium, provided the original work is properly credited. The Creative Commons Public Domain Dedication waiver (http://creativecommons.org/publicdomain/zero/1.0/) applies to the data made available in this article, unless otherwise stated. 


\section{Introduction}

Spot14 (S14), the protein product of the thyroid hormone responsive protein spot14 (Thrsp) gene, is consistently associated with regulation of the de novo fatty acid synthesis pathway. S14 was originally discovered as a protein that was induced in the liver of fasted rats stimulated by lipogenic factors [1]. Mice lacking the S14 gene produce milk with $60 \%$ lower levels of de novo synthesized fatty acids during lactation, compared to wild-type mice, and are resistant to diet-induced obesity [2-4]. We previously characterized gene expression profiles of the mouse mammary gland throughout pregnancy and lactation to identify factors that regulate the sharp increase in fatty acid synthesis observed at parturition [5]. This study of the mammary epithelium revealed that S14 expression was associated with lactogenic differentiation, and its expression mirrored the pattern of fatty acid synthesis enzymes, acetyl CoA carboxylase (ACC), ATP-citrate lyase (ACLY) and fatty acid synthase (FASN) during the transition from pregnancy to lactation. In addition to its role in normal mammary function, S14 was shown to positively regulate de novo fatty acid synthesis and cell proliferation in human breast cancer cells [6,7]. We have recently demonstrated that mammary epithelial cell overexpression of S14 in transgenic mice increases the de novo fatty acids present in milk [4]. Furthermore, we showed that addition of recombinant S14 to the FASN enzyme in vitro reduces the apparent $\mathrm{Km}$, increases the apparent $\mathrm{V}_{\max }$, and increases the synthesis of medium chain fatty acids (MCFA) relative to FASN alone [4]. These observations provide a mechanistic explanation for the described biological effects of S14, particularly in the mammary epithelium during lactation.

Many solid tumors display increased fatty acid synthesis compared to adjacent normal tissue [8]. This is due in part to increased Fasn expression and presumably, increased activity of the FASN enzyme [9]. While it appears that elevated levels of FASN are acquired during tumor progression, its exact role in tumorigenesis is not clear [10]. Increased tumor de novo fatty acid synthesis is predicted to provide several advantages: First, cancer cells are rapidly dividing and have a heightened requirement for membrane phospholipid precursors. Additionally, certain fatty acids can regulate intracellular signaling pathways either by activating signaling molecules or via post-translational modification of pro-tumorigenic kinases, such as Ras and Src [11-13]. Finally, elevated fatty acid synthesis may provide a survival advantage for cancer cells, allowing them to store lipids, which could serve as an energy reserve during the metastatic process. Although the requirement of FASN for breast cancer cell survival and proliferation has been established in vitro and in xenograft models, it is not known whether elevated fatty acid synthesis is sufficient to promote cancer metastasis $[8,10]$. S14 represents a family of proteins that does not have enzymatic activity, but that modulates the activity of de novo fatty acid synthesis pathway enzymes to alter cellular physiology $[4,6,14,15]$.

In human tumors, elevated S14 protein was reported to associate with a poor outcome for patients with invasive breast cancer [16]. Furthermore, reduced breast tumor expression of S14, but not FASN, was accompanied by a lower proliferation index in women treated with conjugated linolenic acid [17]. Despite these studies, little consideration has been given to proteins, like S14, that can enhance FASN activity. Although elevated FASN expression and its activity are features of both the differentiated and the neoplastic mammary epithelium, the timing of FASN activation and its cellular context are critical to both the uses of newly synthesized fatty acids and their biological effects upon mammary cells. Our observation that S14 can stimulate FASN enzymatic activity in vitro led to the hypothesis that overexpression of S14 in the mammary epithelium would support tumorigenesis through its ability to enhance de novo fatty acid biosynthesis. To date, no studies have directly addressed a causal link between S14 activation of de novo fatty acid synthesis and mammary tumorigenesis in vivo. In the present study, we have modulated the levels of de novo synthesized fatty acids in mammary tumors using two transgenic mouse models that either overexpress Thrsp in the mammary gland or lack Thrsp. Overexpression of Thrsp in the mammary glands of MMTV-Neu mice shortened tumor latency and increased tumor proliferation, which was associated with increased levels of MCFA (carbon chain $\leq 16$ ). Conversely, Thrsp loss from MMTVPyMT mice resulted in slower tumor growth, reduced FASN activity, and lower levels of MCFA compared to controls. MMTV-PyMT tumors lacking Thrsp also had reduced levels of phosphorylated Src and Akt, suggesting a possible role for MCFA in potentiating signaling pathways in tumor cells. Surprisingly, tumors from MMTV-Neu mice overexpressing Thrsp had a significant increase the expression of genes associated with luminal differentiation, which was concomitant with decreased lung metastasis. Collectively, these data demonstrate a role for S14 in regulating fatty acid synthesis and mammary tumorigenesis in vivo.

\section{Methods}

\section{Mice}

The MMTV-Neu line 202 mice [18] (FVB/N-Tg(MMT Vneu)202Mul/J; stock number 002376) and the MMTVPyMT [19] (FVB/N-Tg(MMTVPyVT)634Mul/J; stock number 002374) were obtained from The Jackson Laboratory (Bar Harbor, MN, USA). The Thrsp -/- mice [3], herein referred to as $\mathrm{S} 14-/-,(\mathrm{C} 57 \mathrm{Bl} / 6$ background) were kindly provided by Cary Mariash (IU Health Hospital, Indianapolis, IN, USA). S14 -/- mice were backcrossed for ten generations to $\mathrm{FVB} / \mathrm{N}$ mice using a speed congenic approach. All mice were genotyped by PCR amplification of DNA isolated from tail tissue. The MMTV-S14 mice have been described 
previously [4]. Hemizygous MMTV-Neu males were crossed to hemizygous MMTV-S14 females and the resulting offspring genotyped for the presence of both transgenes. Female offspring carrying the $\mathrm{Neu}$ transgene or both the $\mathrm{Neu}$ and S14 transgenes were used for tumor studies. Mice were sacrificed when the largest tumor reached $0.5 \mathrm{~cm}^{3}$.

Male MMTV-PyMT hemizygous mice were crossed with female $\mathrm{S}_{1} 4^{-1-}$ mice and the progeny genotyped for the presence of the MMTV-PyMT transgene. The resulting MMTV-PyMT, S14 ${ }^{+/-}$male mice were crossed with $\mathrm{S} 14^{+/-}$ females. The offspring used for the tumor studies were MMTV-PyMT/S14 ${ }^{-/-}$and MMTV-PyMT/ S14 ${ }^{+/+}$females. MMTV-PyMT/Spot $14^{+/-}$mice were not analyzed in this study. For brevity, the MMTV-PyMT mice are referred to as PyMT and the MMTV-PyMT/S14 $4^{-/-}$mice are referred to as PyMT $/ \mathrm{S} 4^{-/-}$in the text. All animals were maintained in the Center for Comparative Medicine and were provided water and standard rodent chow ad libitum. These studies were approved by the University of Colorado Denver Institutional Animal Care and Use Committee.

\section{Histological analyses}

For immunohistochemistry (IHC), dissected tumors were fixed in 10\% neutral buffer formalin (NBF) and processed by the Pathology Shared Resource of the University of Colorado Cancer Center. Five-micrometer sections were processed for standard staining with hematoxylin and eosin. For IHC analysis of Ki67, antigen retrieval was performed in a pressure cooker using Dako Tissue Retrieval Solution, pH 6 (Dako, Carpinteria, CA, USA; S1699). Following incubation with 3\% $\mathrm{H}_{2} \mathrm{O}_{2}$ (Sigma Aldrich, St. Louis, MO, USA)) in methanol, slides were blocked with Dako Protein Block (Dako, Carpinteria, CA, USA; X0909) and incubated overnight at 4C with rat anti-Ki67 antibody (Dako Carpinteria, CA, USA; M7249) diluted in Dako antibody diluent (Dako, Carpinteria, CA, USA; S0809). The ImmPRESS anti-rat Ig (Vector Labs, Burlingame, CA, USA; MP7444) was used at room temperature for 1 hour and slides were developed using the Dako DAB chromagen kit (Dako, Carpinteria, CA, USA; K3468). Slides were counterstained with Mayer's hematoxylin. Ki67 staining was quantified using the Ventana Medical Systems (Tucson, AZ, USA) VIAS camera and software. Five to twelve nonoverlapping 20x fields in five tissue sections of each group were used to determine the percent of Ki67-positive cells.

For mammary whole mounts, inguinal mammary glands were dissected, fixed in $10 \%$ NBF overnight, stained with carmine alum solution, dehydrated, and mounted between glass slides for visualization. A detailed description has been published elsewhere [20].

Gas chromatography-mass spectrometry (GC-MS) analysis Tumor fatty acids were isolated and analyzed by GC-MS as previously described [4].

\section{FASN activity assay}

Tumors were pulverized in liquid nitrogen and 30 to $60 \mathrm{mg}$ of tissue was lysed in FASN activity buffer to generate cytosolic lysates $(250 \mathrm{mM}$ sucrose, $20 \mathrm{mM}$ HEPES pH 7.6, 2 mM $\mathrm{MgCl}_{2}, 1 \mathrm{mM}$ DTT, 1 mM EDTA, $50 \mathrm{mM} \mathrm{NaF}, 5 \mathrm{mM} \mathrm{NaVO}_{4}$, and $3 \mathrm{x}$ final concentration of Halt ${ }^{\mathrm{tm}}$ Protease Inhibitor cocktail (Thermo Scientific; Waltham, MA, USA)). FASN abundance was quantified for each sample and a volume of cytosolic lysate representing $5 \mu \mathrm{g}$ of FASN per sample was analyzed for FASN activity as previously described $[4,21]$.

\section{Immunoblot analysis}

Tumors were pulverized in liquid nitrogen and protein was extracted from a portion of the tissue by homogenizing in cell lysis buffer (50 mM Tris, $\mathrm{pH} 7.4,150 \mathrm{mM} \mathrm{NaCl}, 2 \mathrm{mM}$ EDTA, $50 \mathrm{mM} \mathrm{NaF}$, 1\% Trition X-100, 1\% DOC, 0.1\% SDS, $1 \mathrm{mM}$ DTT, $5 \mathrm{mM}$ sodium orthovanadate) containing protease inhibitor cocktail $(10 \mu \mathrm{g} / \mu \mathrm{l}$ leupeptin, $10 \mu \mathrm{g} / \mu \mathrm{l}$ aprotinin, $10 \mu \mathrm{M}$ pepstatin A, $1 \mathrm{mM}$ PMSF (L2023, A1153, P4265, and P7626, respectively; Sigma Aldrich, St. Louis, MO, USA)). The homogenates were centrifuged at $13,900 \mathrm{rpm}$ for 15 minutes at $4^{\circ} \mathrm{C}$, and supernatants were collected, snap frozen and stored at $-20^{\circ} \mathrm{C}$ until use. Anti-phospho-Akt Ser473 (\#9271), anti-Akt (\#9272), anti-phospho-Src Tyr416 (\#2101), anti-phospho-PI3K p85 (\#4292), anti-PI3K p85 (\#4257), anti-ACLY (\#4332), anti-ACC (\#3676), and antiActin (\#5125) were obtained from Cell Signaling Technology (Beverly, MA, USA). Anti-PyMT (sc-53481), anti-Neu (sc-284), anti-FASN (sc-20140), anti- $\beta$-tubulin (sc-9104), and anti-Krt18 (sc-28264) were obtained from Santa Cruz Biotechnology (Santa Cruz, CA, USA). The anti-S14 antibody (ab97504) was obtained from Abcam (Cambridge, MA, USA). The monoclonal antibody directed against amino acids 2 to 17 of Src was prepared by the University of Colorado Cancer Center Monoclonal Antibody, Protein Production, and Tissue Culture Shared Resource. Protein bands were visualized using SuperSignal West Pico chemiluminescent substrate (Thermo Scientific, Waltham, MA, USA) and film. ImageJ [22] was used to quantify protein bands. Alternatively, cytosolic extracts were prepared as described in the FASN Activity Assay section, analyzed by SDS-PAGE and imaged/quantified using the LiCOR Odyssey system as described previously [4].

\section{Quantitative PCR (qPCR)}

Gene expression was analyzed by qPCR using primers and FAM-labeled probes or SYBR green chemistry. Primers and probe sequences or catalog numbers are listed in Additional file 1. Unless otherwise indicated, all genes assayed are mouse. Transcript copy number was estimated using a standard curve generated from a known concentration of amplicon for each reaction. Additional details have been described elsewhere [23]. 


\section{Cell culture}

Human breast cancer cells were provided by the University of Colorado Cancer Center Protein Production, Monoclonal Antibody and Tissue Culture Shared Resource and used within 6 months. Cell line identity was validated by STR analysis prior to purchase. Cells were grown in DMEM (Sigma Aldrich, St. Louis, MO, USA) supplemented with $10 \%$ fetal bovine serum (Hyclone, Thermo Scientific, Waltham, MA, USA) and $1 \%$ antibiotic/anti-mycotic solution (Sigma Aldrich, St. Louis, MO, USA). RNA was isolated using the RNEasy Mini Kit (Qiagen, Valencia, CA, USA) and cDNA was prepared using the Verso cDNA synthesis kit (Thermo Scientific, Waltham, MA, USA).

\section{Human microarray data analysis}

Datasets of primary human breast tumors were obtained from the NCBI Gene Expression Omnibus (GEO) or from Oncomine [24]. All data were normalized within datasets. Datasets were individually sorted by S14 expression, and the top and bottom $25 \%$ of the samples were categorized as high and low S14-expressing, respectively. Details of each dataset are listed in Additional file 2. Within the high and low S14-expressing groups, those samples for which either estrogen receptor (ER) IHC status (positive or negative) and intrinsic subtype classification (luminal or basal) were available were used to create $2 \times 2$ contingency tables. Fisher's exact test was used to determine statistical significance for comparisons of tumor subtypes and ER status.

\section{Tumor microarray analysis}

Total RNA was isolated from tumor tissue using Trizol (Life Technologies, Carlsbad, CA, USA). The RNEasy Mini Kit (Qiagen, Valencia, CA, USA) with optional on-column DNAse digestion was used on the final RNA. One hundred micrograms (Neu and Neu/S14 tumors) or 250 micrograms (PyMT and PyMT/S14 ${ }^{-/-}$tumors) of total RNA was prepared for microarray analysis using the Whole Transcript Expression RNA kit (Life Technologies, Carlsbad, CA, USA) and samples were hybridized to mouse 1.1 ST gene arrays (Affymetrix, Santa Clara, CA, USA). Arrays were washed, stained and imaged using the Affymetrix Gene Atlas Microarray System. Raw data were analyzed using Partek Genomic Suite. Select genes were validated by qPCR (see Additional file 3). These studies can be accessed the NCBI GEO database [GSE42708 and GSE55886]. GO enrichment analysis was performed using the Database for Annotation, Visualization and Integrated Discovery (DAVID) bioinformatics resource [25,26]. Only genes with fold change of $+/-1.2$ and $P<0.05$ were considered for analyses, and separate DAVID analyses were performed on genes that were either increased or decreased to allow an interpretation of networks that were enriched in either direction. Full gene lists are available upon request. We presented those GO terms that were enriched $\geq 2$-fold with
$P \leq 0.01$. Four tumors from PyMT and PyMT, $\mathrm{S} 14^{-/-}$mice were analyzed, thirteen tumors from Neu mice, and fourteen tumors from Neu/S14mice.

\section{Statistical analysis}

Unless otherwise stated, the unpaired, two-tailed $t$-test was performed to determine statistical significance.

\section{Results}

We used MMTV-PyMT mice to study the effects of S14 loss because they rapidly develop mammary tumors at a young age, providing an opportunity to observe any delay in tumor latency in mice with altered mammary de novo fatty acid synthesis. Based on the reported link between decreased S14 expression and reduced tumor cell proliferation in human breast cancer [17], we hypothesized that loss of S14 would delay mammary tumor latency. All PyMT mice, and approximately $50 \%$ of PyMT/S14 ${ }^{-/-}$mice in our study formed multiple, large, solid tumors (Figure $1 \mathrm{~A}$ and B). However, in the remaining PyMT/S14 ${ }^{-/-}$mice, we observed large cystic structures (Figure 1C). Once this tumor phenotype emerged, the cysts filled rapidly with fluid, such that the volume of the tumor expanded to $500 \mathrm{~mm}^{3}$ in less than a week (data not shown). The median time to palpable tumor formation in PyMT control female mice was 61 days, while the median time to palpable tumor formation in PyMT/S14 ${ }^{-/-}$female mice was 64 days (Figure 1D). While loss of S14 did not delay the formation of palpable tumors, the solid tumors lacking S14 grew significantly slower than PyMT tumors (Figure 1E). S14 mRNA levels in tumors were evaluated by qPCR (Figure $1 \mathrm{~F}$ ) and expression of Krt18 was examined as a control (Figure 1G).

Mammary glands were collected from 10-week-old PyMT and PyMT/S14 ${ }^{-/-}$females and evaluated as whole mounts, to examine the structure of the ductal tree. Interestingly, we observed striking differences in the mammary gland structures between PyMT and PyMT/ $\mathrm{S} 14^{-1-}$ mice at this age. As previously reported [19], PyMT mice initially developed mammary tumors near the nipple region, while some hyperplastic structures were observed in the middle and at the distal ends of the mammary tree (Figure 2A). By the time PyMT animals were 10 weeks old, the majority of the mammary gland was filled with hyperplastic epithelial structures and very few normal ducts remained (Figure $2 \mathrm{~A}$ and $\mathrm{C}$ ). In contrast, PyMT $/ \mathrm{S} 14^{-/-}$mice formed large, dilated, fluid-filled structures and we observed few solid hyperplasias in 10-week old females (Figure 2B and D). Cell proliferation throughout the gland in PyMT/S14 ${ }^{-/-}$mice was significantly decreased relative to PyMT controls (Figure 2E), while no differences were observed in apoptotic cells between PyMT and PyMT/S14 ${ }^{-1-}$ mice at any age (data not shown).

The effects of S14 overexpression on tumorigenesis were determined using MMTV-Spot14 transgenic female 


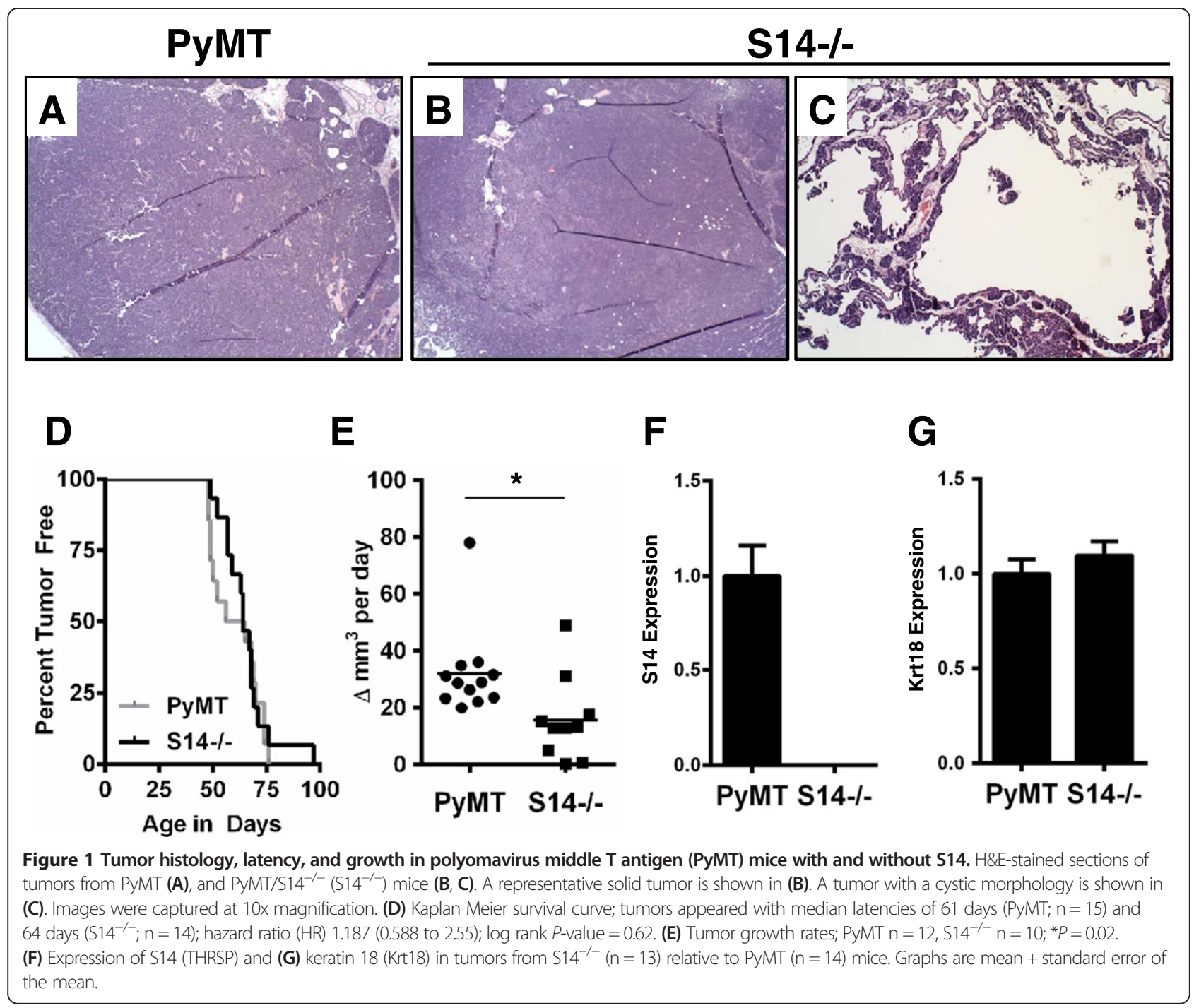

mice crossed with male MMTV-Neu mice. Female MMTVNeu mice develop tumors with a longer latency than MMTV-PyMT mice, with the median time to tumor formation reported to be more than 200 days [18]. Consistent with our hypothesis, overexpression of S14 in MMTV-Neu mice significantly shortened tumor latency (Figure 3A), with median times to palpable tumor formation of 238 days in $\mathrm{Neu} / \mathrm{S} 14$ mice and 279 days in Neu mice. Most Neu mice developed one or two tumors per animal, and the number of tumors detected per mouse was not affected by S14 overexpression (Figure 3B). Tumor cell proliferation was modestly but significantly increased in Neu/S14 compared to Neu mice (Figure 3C). Overexpression of S14 was confirmed by immunoblot analysis (Additional file 4A and $\mathrm{B}$ ) and by GPCR (Additional file 4C) and did not alter the protein or gene expression levels of Neu in mammary tumors (Additional file 4D and E).

We have recently shown that addition of S14 to recombinant FASN enhances the yield of MCFA in vitro, and S14 overexpression in the mammary epithelium increased the amount of MCFA present in milk during lactation [4]. GCMS was used to evaluate the fatty acid profile of tumors from Neu versus Neu/S14 mice and from PyMT versus PyMT/S14 ${ }^{-/-}$(Additional file 5). We observed increased levels of many fatty acids when comparing Neu/S14 to Neu tumors. The largest increase in tumor fatty acids was seen in the MCFA group (chain lengths $\leq 16$ carbons), and there were no significant differences in fatty acids $>16$ carbons (Figure 4A). Conversely, in PyMT/S14 ${ }^{-/-}$tumors, MCFA were significantly lower compared to PyMT tumors, and significant differences were not seen in fatty acids $>16$ carbons (Figure 4B). Analysis of cytosolic lysates revealed that PyMT tumors lacking S14 had equivalent levels of FASN protein as PyMT control tumors (Figure 4C) but had significantly lower FASN enzyme activity (Figure 4D), suggesting that the decreased levels of MCFA in the PyMT/ $\mathrm{S}_{1} 4^{-1-}$ model resulted from reduced de novo fatty acid synthesis. We did not detect any quantitative differences in 


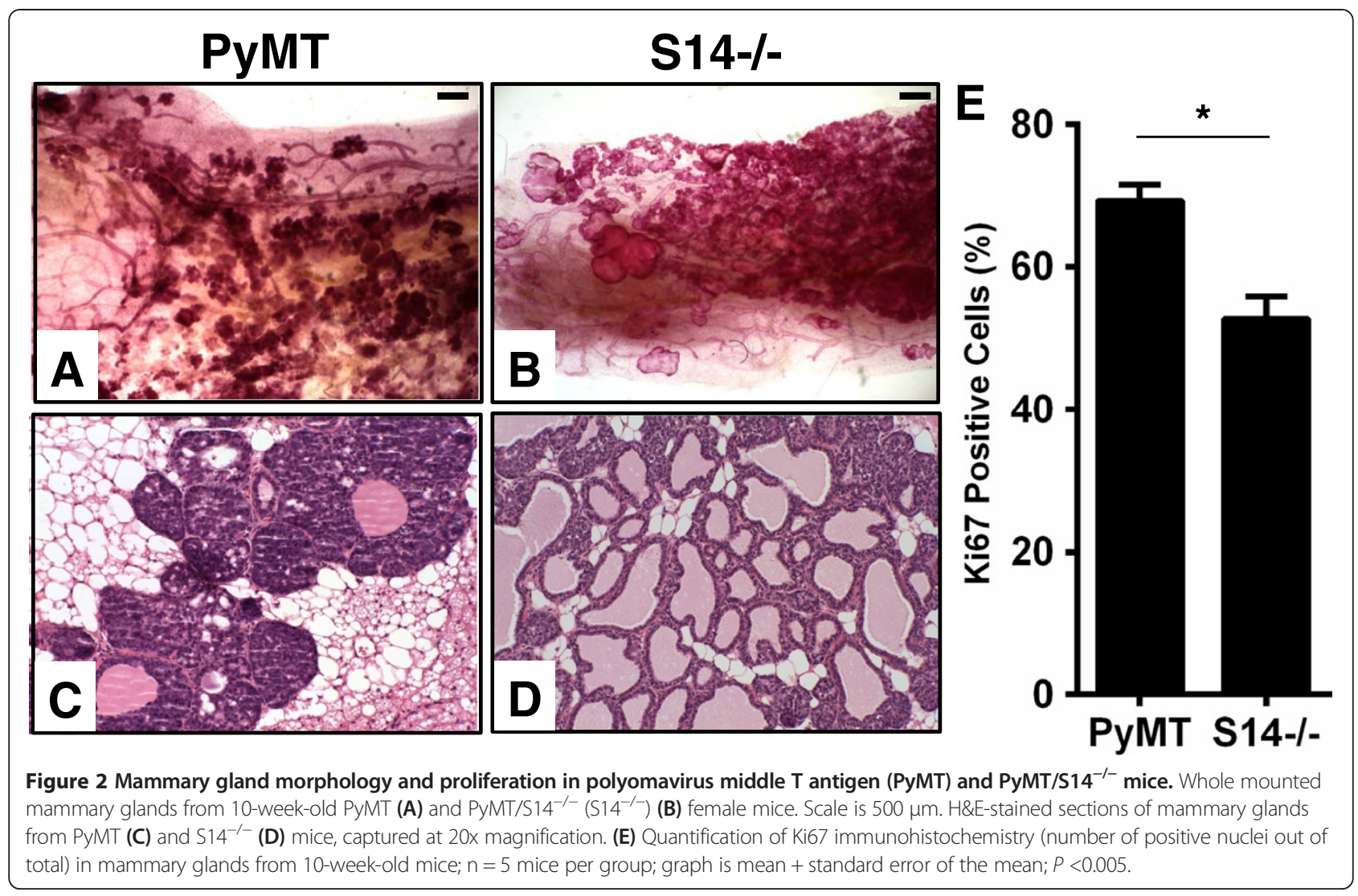

gene or protein levels of ACLY, ACC, or FASN resulting from S14 loss of S14 overexpression in vivo (Additional file 6). In summary, these data indicate that the effects of S14 on the level of MCFA in tumors may result from its ability to modulate the enzymatic activity of FASN.

Lung tissue was collected from all mice in both the PyMT/S14 ${ }^{-/-}$and the Neu/S14 mice and their respective controls, to examine for metastases. No significant differences were found in either the number of mice with lung metastases or in the number of lesions per lung between PyMT and PyMT/S144 ${ }^{-/}$mice (Figure 5A and B), suggesting that the loss of S14, and associated decrease in the proliferation of primary tumor cells, did not impair the process of metastasis in the PyMT model. In contrast, overexpression of S14 in the Neu model resulted in a surprising decrease of lung metastases. Only one of the $15 \mathrm{Neu} / \mathrm{S} 14$ mice examined had visible lung metastases. In comparison, 6/17 Neu mice had metastatic lesions in their lungs

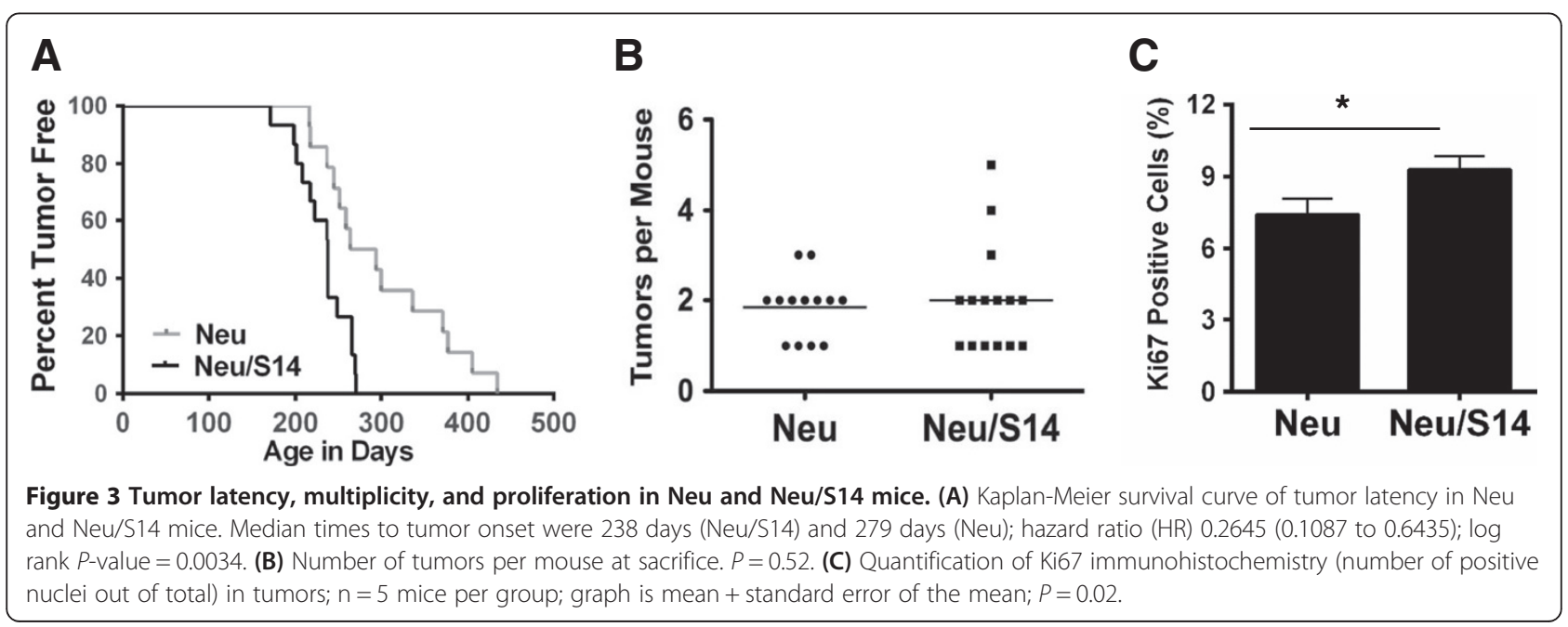




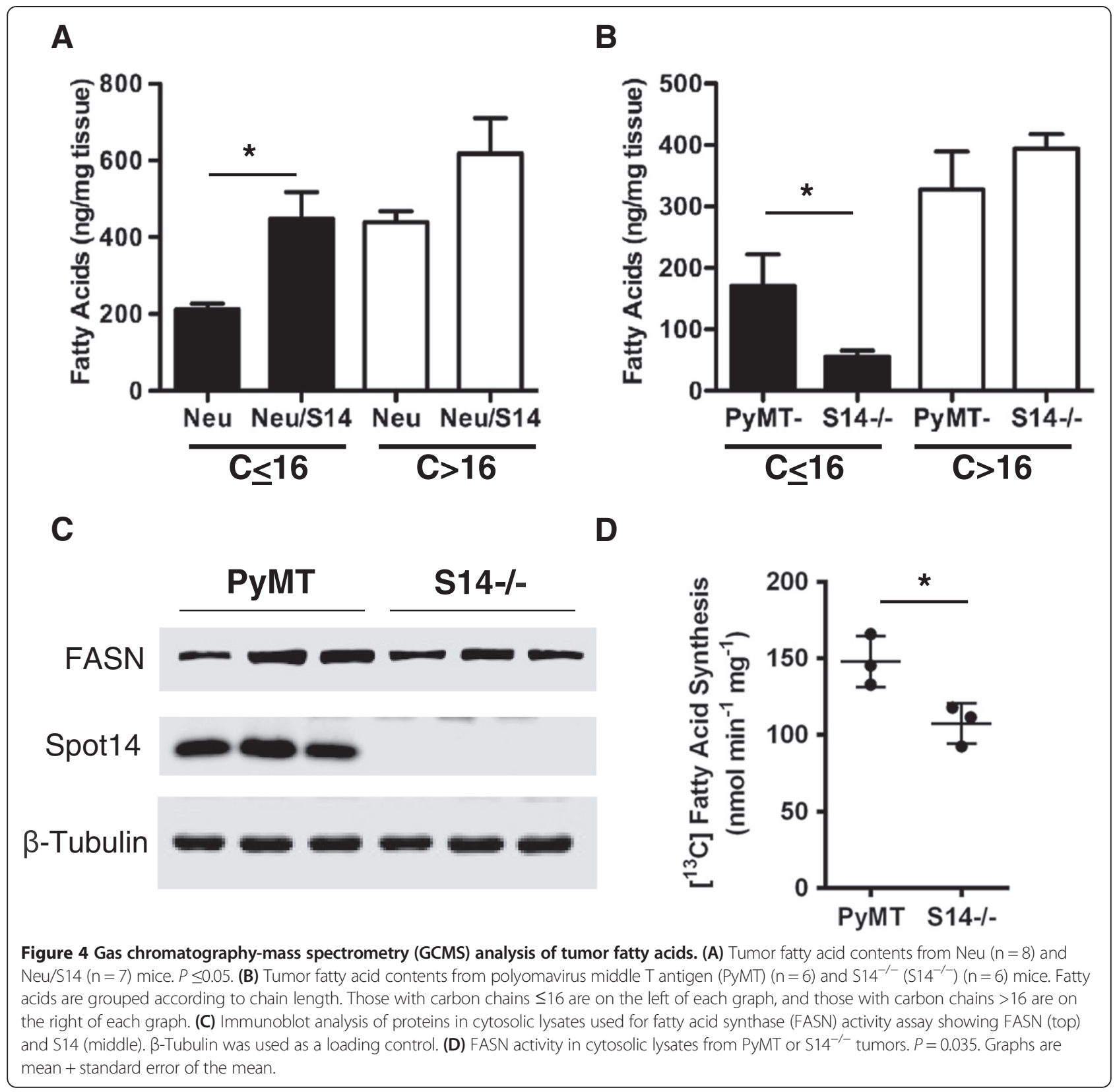

(Figure 5C). Representative lung lesions from both mouse models are shown in Figure 5 (5D-5G). A close examination of primary tumors indicated evidence of lympho-vascular invasion (LVI) in 3/17 Neu mice (data not shown), while no LVI was observed in primary tumors from Neu/S14 mice.

Microarray analysis was performed to better characterize the differences between tumors from PyMT and PyMT/S14 ${ }^{-/-}$mice and also between tumors from Neu and Neu/S14 mice. After identifying genes that were significantly increased or decreased between different experimental groups (PyMT versus PyMT/S14 ${ }^{-/-}$or Neu versus $\mathrm{Neu} / \mathrm{S} 14$ ), we performed gene ontology (GO) enrichment analyses to identify the biological processes that were impacted by S14 manipulation.
In PyMT tumors, the loss of S14 led to reduced expression of genes associated with glucose metabolism, protein kinase activity, and cell proliferation (Additional file 7). In this model, the only significantly enriched GO term for genes that increased in tumors lacking S14 was the cell cycle (fold enrichment $=2.81 ; P=0.002$ ). S14 overexpression in Neu tumors was associated with elevated levels of genes involved in protein translation, positive regulation of growth, and the electron transport chain (Additional file 8). Conversely, tumors overexpressing S14 had decreased levels of genes associated with the development of the heart, skeletal system, and blood vessels (Additional file 9). The genes in these networks appeared to generally represent two categories with regards to the mammary 


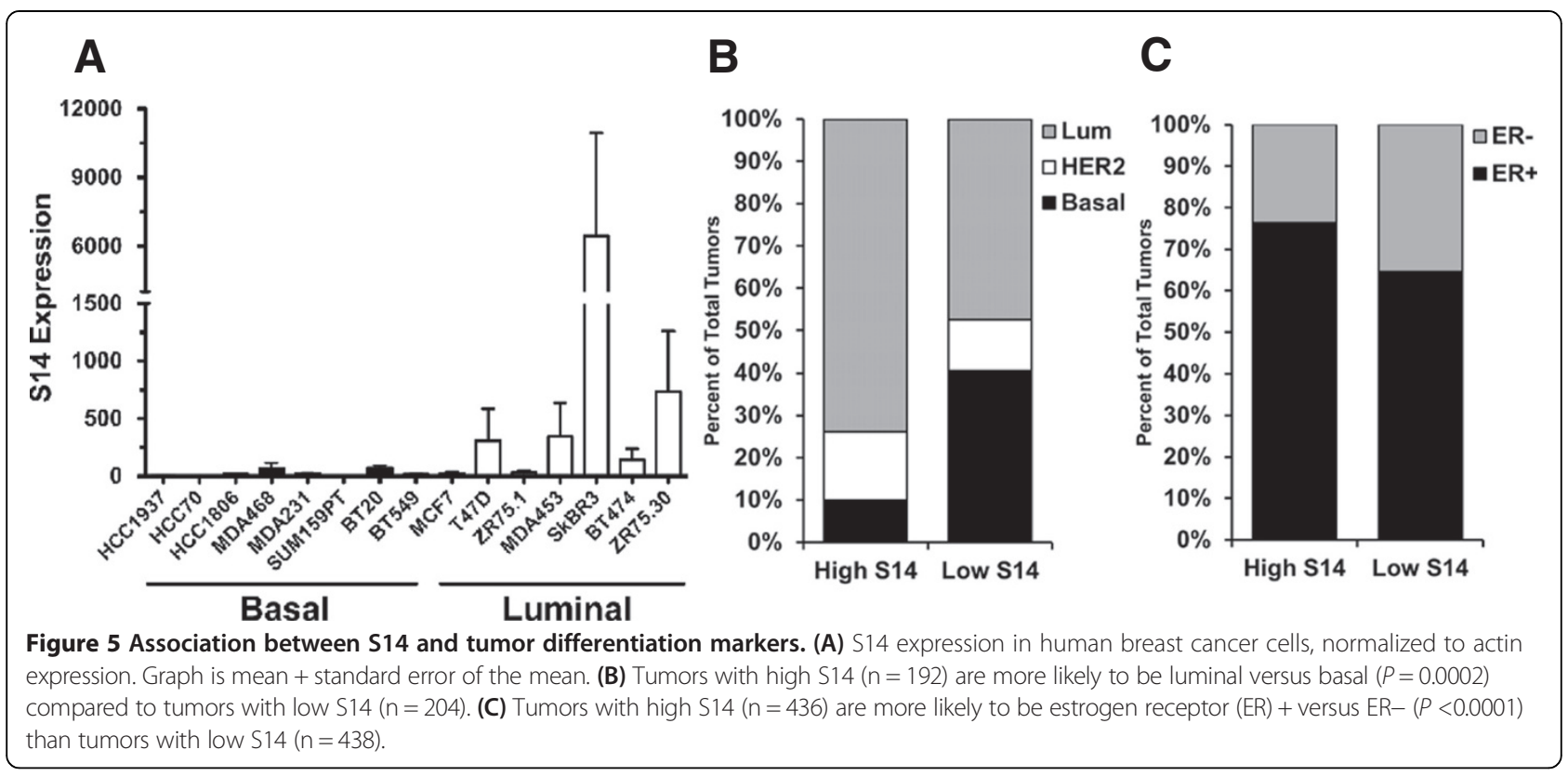

gland and breast cancer. They have been reported to function during early mammary placode formation in the developing embryo (that is, Msx2, Tbx3, Wnt3a, and Fgfr1) or they are involved in breast cancer cell migration, invasion, and proliferation (that is, Barx2, Pdgfrb, Bmp6, and Jak3) [27-36].

When taken together, these data have several implications. First, we observe differential effects of S14 loss or overexpression on metabolic pathways. Loss of S14 from PyMT tumors is linked to decreased glycolytic gene expression, while S14 overexpression in Neu tumors is associated with increased expression of electron transport chain genes. Because PyMT-driven tumors grow so much more rapidly than those in Neu mice, we postulate that tumors from PyMT mice are highly dependent on glycolysis for ATP production and to generate building blocks for cell division. The observation that S14 loss from PyMT tumors leads to a decrease in cell proliferation is not surprising given that these tumors also have a decrease in glycolytic genes, as cell cycle progression and metabolism are tightly intertwined. Conversely, because S14 overexpression in Neu tumors is associated with elevated proliferation, those tumors are also likely more metabolically active, and this is reflected in greater expression of mitochondrial metabolism genes. Overall, the gene expression data are consistent with the differences in tumor growth rates and cell proliferation resulting from S14 loss or overexpression in both mouse models.

In addition to those related to metabolism, we observed differences in genes known to be associated with functional differentiation of the normal mammary gland in $\mathrm{Neu} / \mathrm{S} 14$ tumors (Figure $5 \mathrm{H}$ ). One of the most significantly elevated genes in Neu/S14 tumors was ETS-related transcription factor Elf5, which regulates alveolar differentiation during pregnancy in the mouse mammary gland [37]. The expression of milk protein genes Csn2, Csn1s1, and Csn1s2a was also elevated in Neu/S14 versus Neu tumors (Figure 5H). Recently, Elf5 was shown to repress an EMT-like phenotype during normal mammary gland development and to prevent metastasis in two mouse models of mammary tumorigenesis [38]. When we consider the overall gene expression profile of tumors from $\mathrm{Neu} / \mathrm{S} 14$ mice, we postulate that overexpression of S14 is associated with reduced levels of genes associated with early mammary stem cells and with breast cancer invasion and metastasis, as well as the elevated expression of genes involved with alveolar epithelial differentiation. Altogether, this gene expression profile is consistent with reduced tumor metastasis, associated with S14 overexpression, observed in this model (Figure 5C). Expression of Csn genes was also evaluated in the tumors from PyMT and PyMT/S14 ${ }^{-/-}$mice (Figure 5I). There was no significant difference in the expression of Csn2 and Csn1s2a between PyMT tumors and the solid tumors from PyMT/S14 ${ }^{-/-}$mice (Figure 5I); however, the cystic tumors that formed in PyMT/S14 ${ }^{-1-}$ mice had lower expression of $C s n 2$ and Csn1s2a than those from PyMT mice or than the solid tumors from PyMT/S14 ${ }^{-/-}$ mice, indicating an altered differentiation profile in a subset of PyMT/S14 ${ }^{-1-}$ tumors. Krt18 expression was not different between any tumor groups (Figure 5I).

In human breast cancer cell lines, S14 expression was highest in those representing the luminal subtype compared to those cell lines with basal characteristics (Figure 6A). To determine whether S14 is associated with a particular subtype of human breast tumors, we analyzed publicly available microarray data. Tumors with high S14 expression were significantly more likely to be luminal 


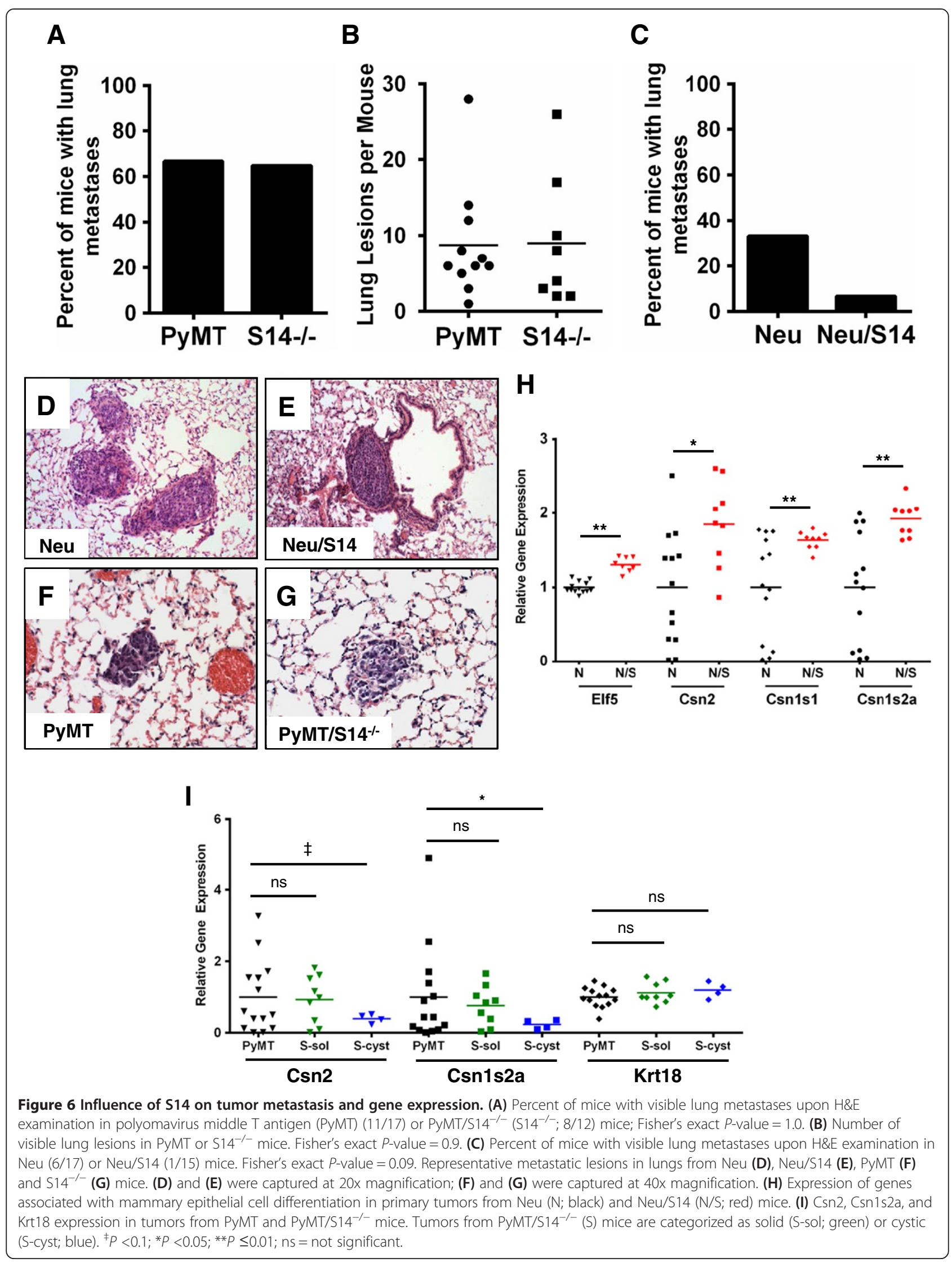


than basal, when considering the intrinsic subtype [39], and were also significantly more likely to be ER+ than ER - (Figure 6B and C). Because the gene expression profile of the Neu/S14 tumors was reminiscent of the differentiated mammary gland, we examined the non-tumor bearing mammary glands from age-matched (10 month old), and diestrus-staged $\mathrm{Neu}$ and Neu/S14 females. Compared to Neu mice, glands from Neu/S14 mice had denser epithelium and apparent hyperplastic epithelial structures (Additional file 10). Further investigation into the connection between S14 and features of luminal differentiation in human breast tumors is warranted.

Growth of PyMT tumors is highly dependent on signaling through Src and the PI3K/Akt pathways [40]. When solid tumors from PyMT mice were compared to PyMT/ S14 ${ }^{-/-}$solid tumors, the phosphorylation of Src and Akt was significantly decreased in solid tumors lacking S14 (Figure 7A and B). Two out of three PyMT tumors appeared to have higher levels of phosphorylated Erk $1 / 2$ than PyMT/S14 ${ }^{-1-}$ tumors, but these differences were not significant when the average ratios of phosphorylated to total Erk1/2 of each group were compared. No differences were observed in the phosphorylation status of the p85 subunit of PI3' kinase (Figure 7A and B). PyMT was expressed in all tumors examined (Figure 7A); however, the levels of PyMT were significantly lower in tumors lacking S14 (Figure 7C). While PyMT does not have any kinase activity, it associates with protein kinases at the cell membrane, and the PyMT protein itself is known to interact with lipid membranes. Little is known about what factors regulate the degradation or turnover of PyMT. The observed differences in Src and Akt phosphorylation could be due to reduced PyMT levels in tumors lacking S14, and changes in all three molecules (Src, Akt, and PyMT) could reflect the alterations in tumor fatty acids, although we did not specifically examine the phospholipid fraction. The levels of actin and Krt18 were equivalent between groups (Figure 7A and C).

\section{Discussion}

In this study, the role of S14 in the regulation of mammary tumor growth was investigated in vivo using

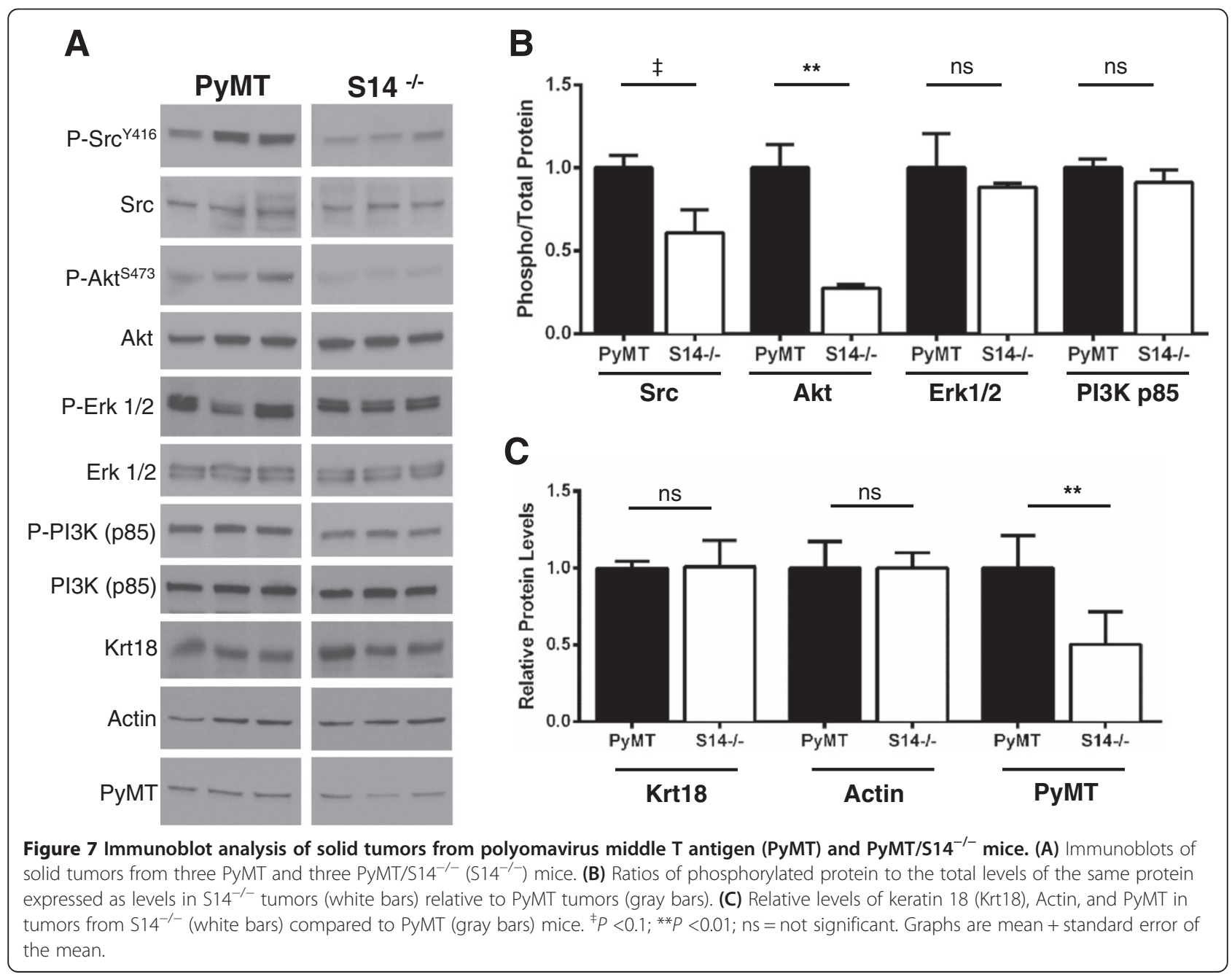


mouse models in which S14 levels were genetically modified. We and others have previously shown that S14 regulates de novo fatty acid synthesis in the normal mammary epithelium during lactation $[3,4]$; and others have shown that $\mathrm{S} 14$ regulates de novo fatty acid synthesis in breast cancer cell lines $[6,41,42]$. We recently showed that S14 altered FASN enzyme catalysis in vitro by increasing the apparent $\mathrm{V}_{\max }$ and decreasing the apparent $\mathrm{Km}$, which resulted in a S14-mediated enhancement of de novo fatty acid synthesis [4]. Furthermore, we showed that S14 transgenic mice produced significantly greater quantities of MCFA in milk during lactation [4]. Here, we have demonstrated a role for S14 in modulating the biology of mammary tumors, potentially through modulation of de novo fatty acid synthesis. Overexpression of S14 in Neu-induced mammary tumors shortened tumor latency and increased tumor cell proliferation (Figure 3); and these differences in tumor growth were associated with elevated tumor levels of MCFA relative to Neu controls (Figure 4). Conversely, the absence of S14 from PyMT-induced mammary tumors was associated with slower tumor growth and decreased proliferation (Figures 1 and 2), which was coincident with decreased FASN activity and lower levels of MCFA in tumors lacking S14 compared to controls (Figure 4). Combined, both tumor models suggest that S14 potentiates de novo fatty acid synthesis in vivo, which could result in altered mammary tumor growth.

Analysis of human breast tumors identified an association between high S14 expression and features of luminal differentiation (Figure 6). Specifically, tumors with high S14 expression were significantly more likely to represent the luminal versus basal subtype, and were more likely to be ER+ than ER-. Consistent with the observation from human breast tumors, tumors from $\mathrm{Neu} / \mathrm{S} 14$ mice also had increased expression of many genes associated with luminal differentiation of mammary epithelial cells, compared to those from Neu mice. Contrary to our hypothesis, overexpression of S14 in Neu-induced tumors resulted in fewer lung metastases compared to controls. These results suggest that tumors from Neu/S14 mice may be less likely to metastasize, in part, because the cells are well differentiated. We have found that overexpression of S14 in normal mouse mammary epithelial cells did not increase the expression of genes associated with lactogenic differentiation (data not shown). Moreover, MMTV-S14 transgenic mice do not display features of lactogenic differentiation in either the gene expression profiles or gland morphology [4]. The frequency of mammary tumor metastasis was also quantified in the PyMT mice with or without S14. While loss of S14 expression was associated with reduced tumor cell proliferation, it did not appear to affect tumor metastasis to the lungs in PyMT mice (Figure 6), suggesting that the effects of S14 on tumor cell proliferation could be independent of processes that govern tumor metastasis.

S14 (reported as Thrsp), one of several genes associated with luminal epithelial differentiation, was found to be downregulated as PyMT-driven mammary tumors progressed from adenomas to carcinomas [43], indicating that S14 may be expressed in a relatively well-differentiated tumor cell type in the PyMT model. Notably, in the PyMT model, only mice lacking S14 expression produced cystic lesions, while PyMT mice formed solid tumors, and the cystic lesions appearing in PyMT/S14 ${ }^{-/-}$mice had reduced expression of casein genes compared to the solid lesions from either group of mice (Figure 5). This observation is consistent with the observed gene expression profile in tumors from Neu/S14 mice [43]. The cystic lesions that developed in the absence of S14 were reminiscent of those that formed in the same model when the mice were treated with the Src inhibitor SKI606 [44]; however, Hebbard et al. reported expression of $\beta$-Casein in the lumens of the lesions from SKI606-treated mice. Although the lesions that form in PyMT mice treated with the Src inhibitor and those from PyMT/S14 ${ }^{-/-}$mice appear similar in morphology, they likely do not have the same molecular characteristics with regards to cellular differentiation. Cumulatively, these data indicate that S14 itself is not sufficient to promote a differentiation program in mammary tumors; rather, S14 may support the proliferation or survival of a differentiated mammary tumor cell type.

Both Src and Akt rely on cellular lipids for their activity [45-47]. Src-family kinases are modified by myristate and palmitate, both of which are MCFA, and myristoylation of c-Src enhances its kinase activity [45]. The lipiddependent activation of Akt occurs through the binding of its plextrin-homology $(\mathrm{PH})$ domain to phosphatidylinositol-trisphosphate $\left(\mathrm{PIP}_{3}\right)$ present in the plasma membrane $[46,47]$. The phosphorylation of Src and Akt at their active sites was decreased in PyMT tumors lacking S14 (Figure 7), suggesting that signal transduction through these kinases may be diminished; however, we did not examine the in vivo activities of these enzymes. In addition, levels of PyMT were reduced in tumors lacking S14. Currently, it is unclear how modulating S14 levels or de novo fatty acid synthesis affects the membrane lipid profiles in either PyMT- or Neu-induced mammary tumors. Furthermore, it is not clear how changes in tumor cell lipid profiles impact the posttranslational modification or activation of critical signaling molecules, or how changes in membrane phospholipids affect the stability of the PyMT oncogene. Our results suggest that changing the tumor fatty acid profile may be a way to alter pro-tumorigenic signaling pathways and reduce the growth and survival of breast cancer cells. Indeed, several studies have reported direct 
relationships between expression and activity of FASN and HER2 signaling pathway activation, which notably affected Akt and Erk activity in cancer cells [48-50].

Chemical inhibition of de novo fatty acid synthesis decreases the proliferation of cultured breast cancer cells, reduces activation of signaling pathways, and in some cases, slows the growth of xenograft tumors [10,48,51-53]; and direct inhibition of FASN has been explored for cancer therapy [48,53-57]. Clearly, modulating fatty acid synthesis activity alters tumor biology. Our study raises several important questions. Are there unique roles for MCFA versus long chain fatty acids in intracellular signaling and tumor cell proliferation? What role do dietary fatty acids play in modulating the growth of mammary tumors that have reduced FASN activity? This work highlights the potential of studying molecules that influence FASN activity as contributors to tumorigenesis and as potential therapeutic targets for the treatment of breast cancer. Furthermore, it suggests FASN activity need not be completely inhibited; instead, novel therapeutics that influence the spectrum of products produced by FASN may be sufficient to alter tumor properties such as signaling pathway activation, cell proliferation, and metastasis.

\section{Conclusions}

S14 enhances FASN catalysis in vitro and the S14 overexpression in the mammary epithelium during lactation facilitated the synthesis of MCFA [4]. Here, we have demonstrated an in vivo role for S14 in modulating de novo fatty acid synthesis in two genetic mouse mammary tumor models. Our finding that altered levels of tumor MCFA are associated with changes in tumor cell proliferation, tumor metastasis, and intracellular signal transduction pathway activation of Src and Akt highlights the importance of studying those molecules that influence FASN activity as potential targets for the treatment of breast cancer. Finally, the potential relationship between S14 expression and luminal differentiation in both mouse and human tumors warrants further investigation.

\section{Additional files}

Additional file 1: QPCR primer/probe sets. Table of gene names and associated primer and probe sequences or Applied Biosystems catalog numbers of commercial primer/probe sets used for GPCR analysis.

Additional file 2: Public microarray datasets. This file contains the GEO ID (if applicable), the number of tumors with low or high S14 expression, the array platform used, the PubMed ID references for each dataset, and the specific analysis for which each dataset was used.

Additional file 3: QPCR validation of microarray data. This file contains a table showing $\mathrm{qPCR}$ results from microarray targets. The mean expression values with standard error of the mean (SEM) for Neu $(n=13)$ and Neu/S14 $(n=14)$ and polyomavirus middle T antigen (PyMT) $(n=14)$ and $\mathrm{S}^{-14^{--}}(\mathrm{n}=9)$ tumors are shown, with fold changes (Neu/S14 versus Neu or S14 ${ }^{-/-}$vs PyMT) and P-values.
Additional file 4: Transgene levels in Neu and Neu_S14 Tumors. (A) Immunoblot of S14 in tumors from Neu and Neu/S14 mice, with $\beta$-Tubulin as a loading control. (B) Quantification of S14 protein levels normalized to B-Tubulin; $P=0.06$. (C) QPCR analysis of S14 gene expression in tumors from Neu $(n=13)$ and Neu/S14 $(n=12)$ mice. $P=0.025$. (D) Immunoblot analysis of Neu (ErbB2) in tumors from Neu and Neu/S14 mice, with Erk as a loading control. (E) QPCR analysis of Neu transgene expression in tumors from $\mathrm{Neu}$ $(n=13)$ and Neu/S14 $(n=12)$ mice.

Additional file 5: Gas chromatography-mass spectrometry (GCMS) tumor fatty acids. This file contains a table of the fatty acids analyzed in tumors from polyomavirus middle T antigen (PyMT) $(n=6)$, PyMT/S14 ${ }^{-/}$ $(n=6)$, Neu $(n=8)$, and Neu/S14 $(n=7)$ mice. Included are the fatty acid chain lengths and saturation, the measured fatty acids in $\mathrm{ng} / \mathrm{mg}$ tissue, the ratios of each group to its respective control, and the $P$-values of the differences between groups.

Additional file 6: Effects of S14 on fatty acid synthesis enzymes. Gene expression and protein levels of ATP-citrate lyase (ACLY), acetyl Co-A carboxylase (ACC), and fatty acid synthase (FASN) in Neu $(n=14)$ and Neu/S14 $(n=15)$ tumors (A and B, respectively) and polyomavirus middle T antigen (PyMT) $(n=4)$ and S14 $4^{--}(n=4)$ tumors ( $C$ and $D$, respectively). Immunoblots were quantified for $\mathrm{Neu}$ and Neu/S14 as well as PyMT and $\mathrm{S}_{14^{-1-}}$ tumors in $\mathrm{E}$ and $\mathrm{F}$, respectively. ns, not significant.

Additional file 7: Gene Ontology (GO) enrichment genes DOWN in polyomavirus middle T antigen (PyMT)_S14null versus PyMT. This file contains the list of significantly enriched $\mathrm{GO}$ (biological process) terms for genes decreased in PyMT/S14 $4^{-/}$vs PyMT tumors, as determined using the Database for Annotation, Visualization and Integrated Discovery (DAVID) resource.

Additional file 8: Gene Ontology (GO) enrichment genes UP in Neu_S14 v Neu. This file contains the list of significantly enriched GO (biological process) terms for genes increased in Neu/S14 vs Neu tumors, as determined using the Database for Annotation, Visualization and Integrated Discovery (DAVID) resource.

Additional file 9: Gene Ontology (GO) enrichment genes DOWN in Neu_S14 v Neu. This file contains the list of significantly enriched GO (biological process) terms for genes decreased in Neu/S14 vs Neu tumors, as determined using the Database for Annotation, Visualization and Integrated Discovery (DAVID) resource.

Additional file 10: MG whole mounts Neu and Neu_S14. This file contains images of whole mounted mammary glands from two each of $\mathrm{Neu}$ and Neu/S14 mice at 10 months of age and in diestrus. Scale for left column (2x) is $1 \mathrm{~mm}$, scale for right column (10x) is $200 \mu \mathrm{m}$.

\section{Abbreviations}

ACC: acetyl Co-A carboxylase; ACLY: ATP-citrate lyase; DAVID: Database for Annotation, Visualization and Integrated Discovery; DMEM: Dulbecco's modified Eagle's medium; ER: estrogen receptor; FAM: 6-carboxyfluoroescein; FASN: fatty acid synthase; GCMS: gas chromatography-mass spectrometry; GEO: NCBI Gene Expression Omnibus; GO: Gene Ontology; H\&E: hematoxylin and eosin; HR: hazard ratio; IHC: immunohistochemistry; KEGG: Kyoto Encyclopedia of Genes and Genomes; Krt18: Keratin 18; LVI: Iympho-vascular invasion; MCFA: medium chain fatty acids; MMTV: mouse mammary tumor virus; PyMT: polyomavirus middle T antigen; S14: Spot 14; THRSP: thyroid hormone responsive protein Spot 14

\section{Competing interests}

The authors declare that they have no competing interests.

\section{Authors' contributions}

EW drafted the manuscript, participated in study design and coordination, performed animal work and tissue analysis, and performed cell culture studies. MR edited the manuscript, performed GC-mass spectrometry analysis of tumor samples and immunoblots and assisted with microarray analysis of tumors. AL performed animal work. NP performed analysis of tissue cell proliferation and immunoblots. PJ provided pathology expertise, evaluated primary tumors for LVI and lungs for metastatic lesions. SA participated in study design and coordination and helped draft the manuscript. All authors have read and approved the final manuscript. 


\section{Acknowledgements}

This work was supported in part by DODBCRP Postdoctoral Fellowship BC098051 awarded to EAW, DOD BCRP Predoctoral Fellowship BC810596 awarded to MCR, and NIH PO1 HD38129PO1 awarded to SMA. The following Shared Resources of the University of Colorado Cancer Center, funded by NCI P30CA046934, were used in support of this research: Pathology Shared Resource and the Protein Production, Monoclonal Antibody and Tissue Culture Shared Resource. The authors would also like to thank Dr Robert Murphy and Christopher Johnson for use of their mass spectrometer and expertise, supported by Colorado Clinical and Translational Sciences Institute 5UL1RR025780, as well as Dr Aik-Choon Tan at the University of Colorado Anschutz Medical Campus for assistance with microarray data analysis.

\section{Author details}

1 Department of Pathology, University of Colorado School of Medicine, University of Colorado Anschutz Medical Campus, Aurora, CO 80045, USA. ${ }^{2}$ Program in Cancer Biology, University of Colorado School of Medicine, University of Colorado Anschutz Medical Campus, 12801 East 17th Avenue, Aurora, CO 80045, USA. ${ }^{3}$ Current Address: Division of Endocrinology, Metabolism, and Diabetes, Department of Medicine, University of Colorado School of Medicine, University of Colorado Anschutz Medical Campus, Aurora, CO 80045, USA. ${ }^{4}$ Current Address: Division of Medical Oncology, Department of Medicine, University of Colorado School of Medicine, University of Colorado Anschutz Medical Campus, Aurora, CO 80045, USA.

Received: 8 May 2014 Accepted: 14 November 2014 Published online: 04 December 2014

\section{References}

1. Tao TY, Towle HC: Coordinate regulation of rat liver genes by thyroid hormone and dietary carbohydrate. Ann NY Acad Sci 1986, 478:20-30.

2. Anderson GW, Zhu Q, Metkowski J, Stack MJ, Gopinath S, Mariash CN: The Thrsp null mouse (Thrsp(tm1 cnm)) and diet-induced obesity. Mol Cell Endocrinol 2009, 302:99-107.

3. Zhu Q, Anderson GW, Mucha GT, Parks EJ, Metkowski JK, Mariash CN: The Spot 14 protein is required for de novo lipid synthesis in the lactating mammary gland. Endocrinology 2005, 146:3343-3350.

4. Rudolph MC, Wellberg EA, Lewis AS, Terrell KL, Merz AL, Maluf NK, Serkova NJ, Anderson SM: Thyroid hormone responsive protein spot14 enhances catalysis of fatty acid synthase in lactating mammary epithelium. J Lipid Res 2014, 55:1052-1065.

5. Rudolph MC, McManaman JL, Hunter L, Phang T, Neville MC: Functional development of the mammary gland: use of expression profiling and trajectory clustering to reveal changes in gene expression during pregnancy, lactation, and involution. J Mammary Gland Biol Neoplasia 2003, 8:287-307.

6. Martel PM, Bingham CM, McGraw CJ, Baker CL, Morganelli PM, Meng ML, Armstrong JM, Moncur JT, Kinlaw WB: S14 protein in breast cancer cells: direct evidence of regulation by SREBP-1C, superinduction with progestin, and effects on cell growth. Exp Cell Res 2006, 312:278-288.

7. Sanchez-Rodriguez J, Kaninda-Tshilumbu JP, Santos A, Perez-Castillo A The spot 14 protein inhibits growth and induces differentiation and cell death of human MCF-7 breast cancer cells. Biochem J 2005, 390:57-65.

8. Kuhajda FP: Fatty acid synthase and cancer: new application of an old pathway. Cancer Res 2006, 66:5977-5980.

9. Ookhtens M, Kannan R, Lyon I, Baker N: Liver and adipose tissue contributions to newly formed fatty acids in an ascites tumor. Am J Physiol 1984, 247:R146-R153.

10. Menendez JA, Lupu R: Fatty acid synthase and the lipogenic phenotype in cancer pathogenesis. Nat Rev Cancer 2007, 7:763-777.

11. Resh MD: Fatty acylation of proteins: new insights into membrane targeting of myristoylated and palmitoylated proteins. Biochim Biophys Acta 1999, 1451:1-16.

12. Resh MD: Regulation of cellular signalling by fatty acid acylation and prenylation of signal transduction proteins. Cell Signal 1996, 8:403-412.

13. Magee Al, Gutierrez L, Marshall CJ, Hancock JF: Targeting of oncoproteins to membranes by fatty acylation. J Cell Sci Supp/ 1989, 11:149-160.

14. Knobloch M, Braun SM, Zurkirchen L, Von Schoultz C, Zamboni N, Arauzo-Bravo MJ, Kovacs WJ, Karalay O, Suter U, Machado RA, Roccio M, Lutolf MP, Semenkovich CF, Jessberger S: Metabolic control of adult neural stem cell activity by Fasn-dependent lipogenesis. Nature 2013, 493:226-230

15. Cunningham BA, Moncur JT, Huntington JT: Kinlaw WB: "Spot 14" protein: a metabolic integrator in normal and neoplastic cells. Thyroid 1998, 8:815-825

16. Wells WA, Schwartz GN, Morganelli PM, Cole BF, Gibson JJ, Kinlaw WB Expression of "Spot 14" (THRSP) predicts disease free survival in invasive breast cancer: immunohistochemical analysis of a new molecular marker. Breast Cancer Res Treat 2006, 98:231-240.

17. McGowan MM, Eisenberg BL, Lewis LD, Froehlich HM, Wells WA Eastman A, Kuemmerle NB, Rosenkrantz KM, Barth RJ Jr, Schwartz GN, Li Z, Tosteson TD, Beaulieu BB Jr, Kinlaw WB: A proof of principle clinical trial to determine whether conjugated linoleic acid modulates the lipogenic pathway in human breast cancer tissue. Breast Cancer Res Treat 2013, 138:175-183.

18. Guy CT, Webster MA, Schaller M, Parsons TJ, Cardiff RD, Muller WJ: Expression of the neu protooncogene in the mammary epithelium of transgenic mice induces metastatic disease. Proc Natl Acad Sci U S A 1992, 89:10578-10582.

19. Guy CT, Cardiff RD, Muller WJ: Induction of mammary tumors by expression of polyomavirus middle $T$ oncogene: a transgenic mouse model for metastatic disease. Mol Cell Biol 1992, 12:954-961.

20. Cui Y, Riedlinger G, Miyoshi K, Tang W, Li C, Deng CX, Robinson GW, Hennighausen L: Inactivation of Stat5 in mouse mammary epithelium during pregnancy reveals distinct functions in cell proliferation, survival, and differentiation. Mol Cell Biol 2004, 24:8037-8047.

21. Rudolph MC, Karl Maluf N, Wellberg EA, Johnson CA, Murphy RC, Anderson SM: Mammalian fatty acid synthase activity from crude tissue lysates tracing (1)(3)C-labeled substrates using gas chromatography-mass spectrometry. Anal Biochem 2012, 428:158-166.

22. Schneider CA, Rasband WS, Eliceiri KW: NIH Image to ImageJ: 25 years of image analysis. Nat Methods 2012, 9:671-675.

23. Rudolph MC, Monks J, Burns V, Phistry M, Marians R, Foote MR, Bauman DE, Anderson SM, Neville MC: Sterol regulatory element binding protein and dietary lipid regulation of fatty acid synthesis in the mammary epithelium. Am J Physiol Endocrinol Metab 2010, 299:E918-E927.

24. Rhodes DR, Yu J, Shanker K, Deshpande N, Varambally R, Ghosh D, Barrette T, Pandey A, Chinnaiyan AM: ONCOMINE: a cancer microarray database and integrated data-mining platform. Neoplasia 2004, 6:1-6.

25. da Huang W, Sherman BT, Lempicki RA: Systematic and integrative analysis of large gene lists using DAVID bioinformatics resources. Nat Protoc 2009, 4:44-57.

26. da Huang W, Sherman BT, Lempicki RA: Bioinformatics enrichment tools: paths toward the comprehensive functional analysis of large gene lists. Nucleic Acids Res 2009, 37:1-13.

27. Phippard DJ, Weber-Hall SJ, Sharpe PT, Naylor MS, Jayatalake H, Maas R, Woo I, Roberts-Clark D, Francis-West PH, Liu YH, Maxson R, Hill RE, Dale TC Regulation of Msx-1, Msx-2, Bmp-2 and Bmp-4 during foetal and postnatal mammary gland development. Development 1996, 122:2729-2737.

28. Davenport TG, Jerome-Majewska LA, Papaioannou VE: Mammary gland, limb and yolk sac defects in mice lacking Tbx3, the gene mutated in human ulnar mammary syndrome. Development 2003, 130:2263-2273.

29. Chu EY, Hens J, Andl T, Kairo A, Yamaguchi TP, Brisken C, Glick A, Wysolmerski JJ, Millar SE: Canonical WNT signaling promotes mammary placode development and is essential for initiation of mammary gland morphogenesis. Development 2004, 131:4819-4829.

30. Vargas AC, McCart Reed AE, Waddell N, Lane A, Reid LE, Smart CE, Cocciardi S, da Silva L, Song S, Chenevix-Trench G, Simpson PT, Lakhani SR: Gene expression profiling of tumour epithelial and stromal compartments during breast cancer progression. Breast Cancer Res Treat 2012, 135:153-165.

31. Eblaghie MC, Song SJ, Kim JY, Akita K, Tickle C, Jung HS: Interactions between FGF and Wnt signals and Tbx3 gene expression in mammary gland initiation in mouse embryos. J Anat 2004, 205:1-13.

32. Pond AC, Bin X, Batts T, Roarty K, Hilsenbeck S, Rosen JM: Fibroblast growth factor receptor signaling is essential for normal mammary gland development and stem cell function. Stem Cells 2013, 31:178-189.

33. Stevens TA, Meech R: BARX2 and estrogen receptor-alpha (ESR1) coordinately regulate the production of alternatively spliced ESR1 isoforms and control breast cancer cell growth and invasion. Oncogene 2006, 25:5426-5435. 
34. Kuzmanov A, Hopfer U, Marti P, Meyer-Schaller N, Yilmaz M, Christofori G: LIM-homeobox gene 2 promotes tumor growth and metastasis by inducing autocrine and paracrine PDGF-B signaling. Mol Oncol 2014, 8:401-416.

35. Lian WJ, Liu G, Liu YJ, Zhao ZW, Yi T, Zhou HY: Downregulation of BMP6 enhances cell proliferation and chemoresistance via activation of the ERK signaling pathway in breast cancer. Oncol Rep 2013, 30:193-200.

36. Ye Q, Kantonen S, Gomez-Cambronero J: Serum deprivation confers the MDA-MB-231 breast cancer line with an EGFR/JAK3/PLD2 system that maximizes cancer cell invasion. J Mol Biol 2013, 425:755-766.

37. Harris J, Stanford PM, Sutherland K, Oakes SR, Naylor MJ, Robertson FG, Blazek KD, Kazlauskas M, Hilton HN, Wittlin S, Alexander WS, Lindeman GJ, Visvader JE, Ormandy CJ: Socs2 and elf5 mediate prolactin-induced mammary gland development. Mol Endocrinol 2006, 20:1177-1187.

38. Chakrabarti R, Hwang J, Andres Blanco M, Wei Y, Lukacisin M, Romano RA, Smalley K, Liu S, Yang Q, Ibrahim T, Mercatali L, Amadori D, Haffty BG, Sinha S, Kang Y: Elf5 inhibits the epithelial-mesenchymal transition in mammary gland development and breast cancer metastasis by transcriptionally repressing Snail2. Nat Cell Biol 2012, 14:1212-1222.

39. Perou CM, Sorlie T, Eisen MB, van de Rijn M, Jeffrey SS, Rees CA, Pollack JR, Ross DT, Johnsen H, Akslen LA, Fluge O, Pergamenschikov A, Williams C, Zhu SX, Lonning PE, Borresen-Dale AL, Brown PO, Botstein D: Molecular portraits of human breast tumours. Nature 2000, 406:747-752.

40. Dilworth SM: Polyoma virus middle $T$ antigen and its role in identifying cancer-related molecules. Nat Rev Cancer 2002, 2:951-956.

41. Moncur JT, Park JP, Memoli VA, Mohandas TK, Kinlaw WB: The "Spot 14" gene resides on the telomeric end of the 11 q13 amplicon and is expressed in lipogenic breast cancers: implications for control of tumor metabolism. Proc Natl Acad Sci U S A 1998, 95:6989-6994.

42. Donnelly C, Olsen AM, Lewis LD, Eisenberg BL, Eastman A, Kinlaw WB: Conjugated linoleic acid (CLA) inhibits expression of the Spot 14 (THRSP) and fatty acid synthase genes and impairs the growth of human breast cancer and liposarcoma cells. Nutr Cancer 2009, 61:114-122.

43. Kouros-Mehr H, Bechis SK, Slorach EM, Littlepage LE, Egeblad M, Ewald AJ, Pai SY, Ho IC, Werb Z: GATA-3 links tumor differentiation and dissemination in a luminal breast cancer model. Cancer Cell 2008, 13:141-152

44. Hebbard L, Cecena G, Golas J, Sawada J, Ellies LG, Charbono A, Williams R, Jimenez RE, Wankell M, Arndt KT, DeJoy SQ, Rollins RA, Diesl V, Follettie M, Chen L, Rosfjord E, Cardiff RD, Komatsu M, Boschelli F, Oshima RG: Control of mammary tumor differentiation by SKI-606 (bosutinib). Oncogene 2011, 30:301-312.

45. Patwardhan P, Resh MD: Myristoylation and membrane binding regulate c-Src stability and kinase activity. Mol Cell Biol 2010, 30:4094-4107.

46. Frech M, Andjelkovic M, Ingley E, Reddy KK, Falck JR, Hemmings BA: High affinity binding of inositol phosphates and phosphoinositides to the pleckstrin homology domain of RAC/protein kinase B and their influence on kinase activity. J Biol Chem 1997, 272:8474-8481.

47. James SR, Downes CP, Gigg R, Grove SJ, Holmes AB, Alessi DR: Specific binding of the Akt-1 protein kinase to phosphatidylinositol 3,4,5-trisphosphate without subsequent activation. Biochem J 1996, 315:709-713.

48. Puig T, Aguilar H, Cufi S, Oliveras G, Turrado C, Ortega-Gutierrez S, Benhamu B, Lopez-Rodriguez ML, Urruticoechea A, Colomer R: A novel inhibitor of fatty acid synthase shows activity against HER2+ breast cancer xenografts and is active in anti-HER2 drug-resistant cell lines. Breast Cancer Res 2011, 13:R131.

49. Vazquez-Martin A, Colomer R, Brunet J, Lupu R, Menendez JA: Overexpression of fatty acid synthase gene activates HER1/HER2 tyrosine kinase receptors in human breast epithelial cells. Cell Prolif 2008, 41:59-85.

50. Puig T, Turrado C, Benhamu B, Aguilar H, Relat J, Ortega-Gutierrez S, Casals G, Marrero PF, Urruticoechea A, Haro D, Lopez-Rodriguez ML, Colomer R: Novel Inhibitors of Fatty Acid Synthase with Anticancer Activity. Clin Cancer Res 2009, 15:7608-7615.

51. Flavin R, Peluso S, Nguyen PL, Loda M: Fatty acid synthase as a potential therapeutic target in cancer. Future Oncol 2010, 6:551-562.

52. Jin Q, Yuan LX, Boulbes D, Baek JM, Wang YN, Gomez-Cabello D, Hawke DH, Yeung SC, Lee MH, Hortobagyi GN, Hung MC, Esteva PJ: Fatty acid synthase phosphorylation: a novel therapeutic target in HER2overexpressing breast cancer cells. Breast Cancer Res 2010, 12:R96.
53. Turrado C, Puig T, Garcia-Carceles J, Artola M, Benhamu B, Ortega-Gutierrez S, Relat J, Oliveras G, Blancafort A, Haro D, Marrero PF, Colomer R, Lopez-Rodriguez ML: New synthetic inhibitors of fatty acid synthase with anticancer activity. J Med Chem 2012, 55:5013-5023.

54. Carvalho MA, Zecchin KG, Seguin F, Bastos DC, Agostini M, Rangel AL, Veiga SS, Raposo HF, Oliveira HC, Loda M, Coletta RD, Graner E: Fatty acid synthase inhibition with Orlistat promotes apoptosis and reduces cell growth and lymph node metastasis in a mouse melanoma model. Int J Cancer 2008, 123:2557-2565.

55. Alli PM, Pinn ML, Jaffee EM, McFadden JM, Kuhajda FP: Fatty acid synthase inhibitors are chemopreventive for mammary cancer in neu- $\mathrm{N}$ transgenic mice. Oncogene 2005, 24:39-46.

56. Murata S, Yanagisawa K, Fukunaga K, Oda T, Kobayashi A, Sasaki R, Ohkohchi N: Fatty acid synthase inhibitor cerulenin suppresses liver metastasis of colon cancer in mice. Cancer Sci 2010, 101:1861-1865.

57. Pizer ES, Wood FD, Heine HS, Romantsev FE, Pasternack GR, Kuhajda FP: Inhibition of fatty acid synthesis delays disease progression in a xenograft model of ovarian cancer. Cancer Res 1996, 56:1189-1193.

\section{Submit your next manuscript to BioMed Central and take full advantage of:}

- Convenient online submission

- Thorough peer review

- No space constraints or color figure charges

- Immediate publication on acceptance

- Inclusion in PubMed, CAS, Scopus and Google Scholar

- Research which is freely available for redistribution

Submit your manuscript at www.biomedcentral.com/submit
C BioMed Central 